Nordisk Tidsskrift for Kriminalvidenskab 2007

\title{
DET STIGENDE ANTAL RETSPSYKIATRISKE PATIENTER
}

\section{Af lektor Gorm Gabrielsen og ledende overlæge Peter Kramp}

The Danish penal code $\S 16$ (1) says that "Persons who, at the time of the act, were irresponsible owing to mental illness or similar conditions or a pronounced mental retardation are not punishable". If "non punishable", the court will pass one of the following treatment sanctions: (a) placement in a psychiatric ward; (b) psychiatric treatment, or (c) outpatient psychiatric treatment. Among (b) and (c) 95\% is under supervision by a probation officer and these persons comprice the material. Treatment continues until the sanction is abolished by the court. Between 1970 and 1990, the number of new forensic psychiatric patients increased with an annual growth rate of $6.5 \%$. In recent years, however, this growth rate has rapidly increased. Between 2003 and 2006, the annual growth rate was $15 \%$. This very high rate of growth is at least partially attributable to a higher growth rate for women as compared to men.

Oplæggets hovedærinde er en påpegning af stigningen i antallet af retspsykiatriske patienter i Danmark. I oplægget skitseres kort rammer og betingelser for området - og derefter beskrives udviklingen $\mathrm{i}$ antallet af retspsykiatriske patienter.

Den danske straffelovs $\S 16$, stk. 1, pkt. 1, lyder:"' Personer, der på gerningstidspunktet var utilregnelige pga. sindssygdom eller tilstande, der må ligestilles hermed, straffes ikke". De "ligestillede" tilstande omfatter f.eks. konfusionstilstande pga. neuroglykopeni eller i forbindelse med epileptiske anfald. Disse tilstande spiller talmæssigt ingen rolle og vil ikke blive nærmere omtalt. Som det fremgår skal to betingelser for straffrihed være opfyldte - personen skal være sindssyg og af den grund være utilregnelig. Psykiateren afgør ved en mentalundersøgelse, hvorvidt personen er sindssyg eller var sindssyg på gerningstidspunktet, dvs. psykotisk i lægevidenskabelig forstand. Der eksisterer ikke noget "juridisk" sindssygdomsbegreb. Herefter afgør retten, om den pågældende også er eller var "utilregnelig". Dette begreb - "utilregnelig" - er blevet karakteriseret som meningstomt og er alene indsat i lovteksten for at sikre, at det i sidste ende er retten, og ikke psykiateren, der afgør, om en person, der er fundet skyldig i en kriminel handling, skal være straffri. Al erfaring viser, at domstolene næsten undtagelsesvis finder sindssyge kriminelle "utilregnelige" (Kramp et al. 1996). Det sker måske en eller højst to gange om året, at en sindssyg kriminel findes "tilregnelig", og det sker typisk i tilfælde, hvor

\footnotetext{
* Title in English: The Increasing Number of Forensic Psychiatric Patients. Original in Danish.
} 
den mentalundersøgende retspsykiater selv har været $\mathrm{i}$ tvivl om psykosediagnosen. Denne centrale bestemmelse - straffelovens § 16 - har været uændret siden 1973/75, om end der er sket en vis modernisering af ordlyden.

I stedet for straf bliver de psykisk syge idømt en psykiatrisk særforanstaltning, hvoraf der findes tre hovedgrupper - dom til anbringelse i psykiatrisk afdeling, dom til behandling i psykiatrisk afdeling og dom til ambulant behandling ved psykiatrisk afdeling. Blandt de to sidstnævnte grupper - de behandlingsdømte og personer med dom til ambulant behandling - har $95 \%$ også tilsyn af kriminalforsorgen (Kramp \& Gabrielsen 2001). De anbringelsesdømte indlægges på en (rets)psykiatrisk afdeling og kan ikke udskrives, før retten ændrer foranstaltningen til en behandlingsdom. Disse patienter har derfor ikke behov for den kontrol og støtte, som et tilsyn indebærer.

De behandlingsdømte skal som udgangspunkt indlægges på en psykiatrisk afdeling, men herefter er det den aktuelle overlæge, der træffer beslutning om udskrivelse til ambulant behandling (og tilsyn af kriminalforsorgen), ligesom overlægen sammen med kriminalforsorgen kan eller skal træffe bestemmelse om, at patienten kan genindlægges. Ved en dom til ambulant behandling er udgangspunktet ambulant psykiatrisk behandling (og tilsyn af kriminalforsorgen), men som hovedregel vil dommen åbne mulighed for, at overlægen sammen med kriminalforsorgen kan træffe bestemmelse om (gen)indlæggelse.

Kriminelle med andre lidelser end psykosesygdomme kan også blive idømt en af ovennævnte psykiatriske særforanstaltninger (straffelovens § 69), men traditionelt er anvendelsesområdet snævert. Det kan f.eks. dreje sig om personer med en skizotypisk sindslidelse eller lette til middelsvære neurobiologiske udviklingsforstyrrelser (de svære er omfattet af $\S 16$, stk. 1), visse ikke-psykotiske demenstilstande mv. Derimod anvendes psykiatriske særforanstaltninger som udgangspunkt ikke over for misbrugere eller personer med selv udtalte personlighedsforstyrrelser.

Fra 1977 har de enkelte kriminalforsorgsafdelinger indberettet antal klienter i tilsyn samt deres juridiske status - dvs. betinget dømte, prøveløsladte, samfundstjeneste osv., herunder også foranstaltningsdømte, dvs. retspsykiatriske patienter - til statistikenheden, Direktoratet for Kriminalforsorgen.

Ifølge gældende administrative forskrifter (Rigsadvokaten 2002 og 2007) bør alle, der er sigtet for en straffelovsovertrædelse, som efter gældende praksis kan føre til en (betinget eller ubetinget) frihedsstraf mentalundersøges. Denne hovedregel har været uændret siden 1977.

Sindssyge kan idømmes bødestraf, som fx anvendes i tilfælde af butiks- og cykeltyveri, og i disse tilfælde foretages ikke mentalundersøgelse. Danmark anvender ikke "diversion", dvs. at sigtede, der er psykisk syge, overføres til almenpsykiatrien 
- typisk efter aftale med anklager, forsvarer og dommer - før der overhovedet er rejst en sag. I Danmark vil udgangspunktet være at rejse sag og fælde dom. Antallet af retspsykiatriske patienter vil derfor afspejle det reelle omfang af registreret kriminalitet begået af psykisk syge og fx ikke tilfældige udsving i hvem og hvor mange, der bliver "diverted".

Sammenfattende ses herefter, at den danske straffelovs bestemmelse om psykisk syge medfører, at det er muligt nøje at følge udviklingen i antallet af retspsykiatriske patienter, det vil sige, i hvilket omfang psykisk syge begår kriminalitet, og at data er valide og unbaised.

\section{Udviklingen i retspsykiatriske patienter $1977-2004$}

Vi har tidligere beskrevet udviklingen af retspsykiatriske patienter op til og med 2004 (Kramp \& Gabrielsen 2005). Fra 1977 har de enkelte kriminalforsorgsafdelinger som nævnt hver måned indberettet antal klienter i tilsyn samt deres juridiske status. Det månedlige antal af retspsykiatriske klienter betegner vi prævalensen.

Figur 1 viser den månedlige prævalens fra januar 1980 til december 2004 af retspsykiatriske patienter med tilsyn af kriminalforsorgen.

Figur 1. Provalensen af retspsykiatriske patienter 1975 til 2004

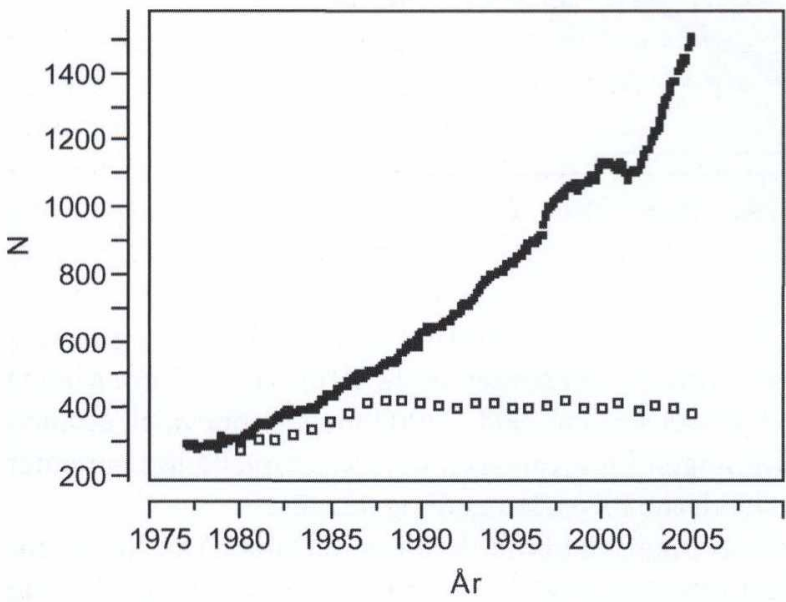

Månedlig prævalens

$\square$ Anmeldte straffelovsovertrædelser (i 1000) (Minus butiks- og cykeltyveri)

Fra 1980 til 2000 voksede antallet af klienter eksponentielt med en årlig vækstrate på $6,8 \%$. I 2000 - 2002 skete der et lille fald, som skyldes, at visse af de psykiatriske særforanstaltninger blev tidsbegrænsede til tre eller (oftest) fem år. I forbindelse hermed skulle anklagemyndigheden indbringe alle domme, idømt før lovændringen, for retten med henblik på ændring af dommen i henhold til de nye 
regler. Dette medførte, at en række domme blev ophævet, hvorfor vækstraten i en periode på et par år var negativ. Fra 2002 ses imidlertid igen en kraftig vækst, nu med en eksponentiel årlig stigning på ca. $11 \%$. I absolutte tal er antallet af patienter i perioden 1980 til 2004 øget fra ca. 300 i 1980 til ca. 1650 i 2004. Samtidig ses, at det årlige antal anmeldte straffelovsovertrædelser (minus butiks- og cykeltyveri, jf. tidligere) fra omkring 1989 har været uændret med en faldende tendens de seneste år, hvor stigningen $\mathrm{i}$ antallet af retspsykiatriske patienter har været størst.

Fra 1989 kendes også for hver måned antallet af nye retspsykiatriske patienter med tilsyn af kriminalforsorgen, den månedlige incidens, Figur 2.

Figur 2. Incidens og model, retspsykiatriske patienter 1989 til 2004

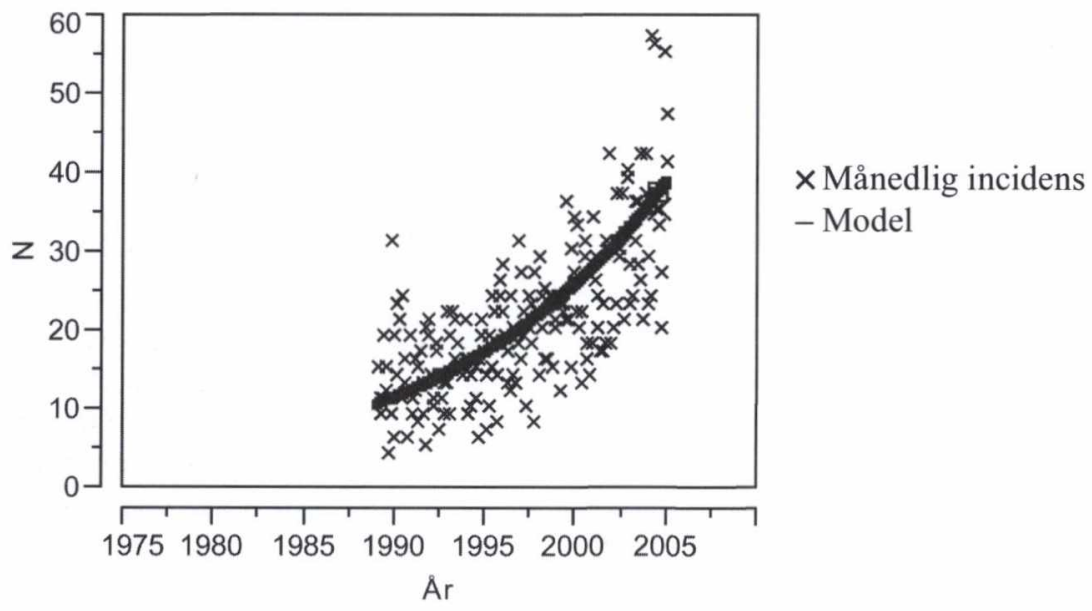

Det ses umiddelbart, at også incidensen øges kraftigt - med voksende vækstrate. For perioden 2002 til 2004 estimeres vækstraten til $12 \%$ pro anno. Der er ingen statistisk signifikant forskel på vækstraten 2004 - 2004 mellem prævalen og incidens, hvilket betyder, at stigningen i prævalensen skyldes et øget antal patienter og fx ikke, at foranstaltningstiderne bliver længere og længere.

Som nævnt indgår de anbringelsesdømte ikke i materialet. Antallet af anbringelsesdømte er imidlertid begrænset, ca. 100 personer i alt, og også dette antal stiger, om end ikke helt så voldsomt som de behandlingsdømte og dømte til ambulant behandling (Kramp \& Gabrielsen 2003).

Materialet viser alene udviklingen i antallet, men det siger ikke noget om diagnoser eller kriminalitet. Undersøgelser af retspsykiatriske patienter i København $(\mathrm{H}: \mathrm{S})$ - og det drejer sig om ca. en tredjedel af landets retspsykiatriske patienter 
- viser, at stigningen næsten udelukkende skyldes, at stadig flere skizofrene registreres for at have begår kriminalitet; der er således ikke tale om, at flere ikkepsykotiske kriminelle overføres til psykiatrien ("psychiatrization of the criminals") (Kramp \& Gabrielsen 2004). Blandt de psykisk syge kriminelle, og det vil i praksis sige skizofrene, begår ca. $75 \%$ personfarlig kriminalitet, det vil sige vold inkl. drab, brandstiftelse, sædelighedskriminalitet og røveri, kun ca. $25 \%$ er dømt for berigelseskriminalitet. Blandt kriminelle, som ikke er psykisk syge (det vil sige er idømt fængselsstraffe) er forholdet omvendt - $25 \%$ er dømt for personfarlig kriminalitet, $75 \%$ for berigelseskriminalitet.

\section{Mulige forklaringer}

En forklaring på en så systematisk og voldsom vækst må søges i strukturelle årsager - og her kunne en forklaring være en omfattende omlægning af det psykiatriske behandlingssystem. Den enkleste, mest nærliggende - og blandt politikere og nogle psykiatere mest upopulære - forklaring er, at der er nedlagt for mange psykiatriske sengepladser - i Danmark fra ca. 8000 sengepladser i 1980 til ca. 3700 i 2004, og sengetallet falder stadig. En nedlagt sengeplads betyder selvsagt ikke en ny retspsykiatrisk patient, men for få psykiatriske senge medfører, at fx debuterende skizofrene patienter ikke kan få den længerevarende indlæggelse, som ofte er nødvendig for at bedre patientens tilstand. Neuroleptisk behandling er som udgangspunkt det nødvendige grundlag, men $\mathrm{fx}$ en veltilrettelagt miljøterapi kan være med til at bringe ro i patientens indre kaos, ligesom den begrænsning af stimuli, som en indlæggelse indebærer, i sig selv vil være kurativ. Skizofreni er en hjernesygdom, og en central patologisk mekanisme er en defekt filterfunktion $i$ thalamus (Glenthøj et al 1999). Det forekommer derfor rationelt at begrænse stimuli i aktive sygdomsfaser, det vil sige indlægge patienten og, når den akutte urofase er overstået, lade patienten forblive indlagt på en rolig, gerne åben afdeling til vedvarende bedring er indtrådt. Men en kortvarig indlæggelse på en lukket, urolig modtageafdeling gør hverken fra eller til.

Disse mere teoretiske overvejelser understøttes nu af empiriske undersøgelser fra flere lande. Tjekkiet har ikke deinstitutionaliseret det psykiatriske behandlingssystem i perioden 1949 - 2000, og i hele denne periode er vold begået af skizofrene patienter (inkl. vold under indlæggelse) ikke steget, mens stofmisbrug blandt patienterne er øget de sidste 10 år (Vevera et al 2005). Irland har deinstitutionaliseret, men i forskellig omfang i forskellige dele af landet. Der er en klar statistisk signifikant negativ korrelation mellem disponible psykiatriske sengepladser og forbrug af retspsykiatriske sengepladser - des færre almenpsykiatriske senge, des større forbrug af retspsykiatriske senge (O’Neill et al 2002). I Danmark belægger de retspsykiatriske patienter nu ca. $20 \%$ af alle almenpsykiatriske sengepladser (Amtrådsforeningen 2004). 
En større, international multicenterundersøgelse (Hodgins et al 2006) har vist, at stofmisbrug ikke var associeret med en patients overflytning fra almenpsykiatrien til retspsykiatrien, at patienter udskrevet fra almenpsykiatrien, frembød flere (alvorlige) symptomer ved udskrivelsen end tilfældet var for patienter, der blev udskrevet fra retspsykiatrisk afdelinger, og at signifikant flere almenpsykiatriske end retspsykiatriske var indblandet i en voldelig periode i løbet af en to års opfølgningsperiode efter udskrivelse. Forfatterne konkluderer: .." that the dramatic increase in forensic beds is due to the failure by general adults services to provide treatments that reduces aggressive behaviour and associated characteristics among male patients with schizophrenia and schizo-affective disorder".

\section{Nye retspsykiatriske patienter 2003 - 2006}

Siden 1. januar 2003 har Kriminalforsorgen benyttet sit eget IT-baserede klientsystem. Systemet giver mulighed for oplysninger om CPR-nummer (dvs. bl.a. køn og alder), domsdato og dato for udgåelse af tilsyn samt oplysning om den kriminalitet, dommen omfatter. Klientsystemet omfatter oplysninger om 1774 personer med nye domme i årene 2003 til 2006. Ved en ny dom forstås her en dom, der ikke er en ændring eller en ny dom under forløbet af en retspsykiatrisk særforanstaltning.

Vi har benyttet oplysninger fra klientsystemet til at foretage nogle foreløbige analyser af de 1774 nye retspsykiatriske domme i perioden 2003 til 2006. En mere detaljeret analyse vil blive publiceret senere.

De nye tal giver anledning til, at man kan forlænge kurven over månedlige incidencer til også at omfatte årene 2005 og 2006, figur 3.

Figur 3. Incidens og model, retspsykiatriske patienter 1989 til 2006

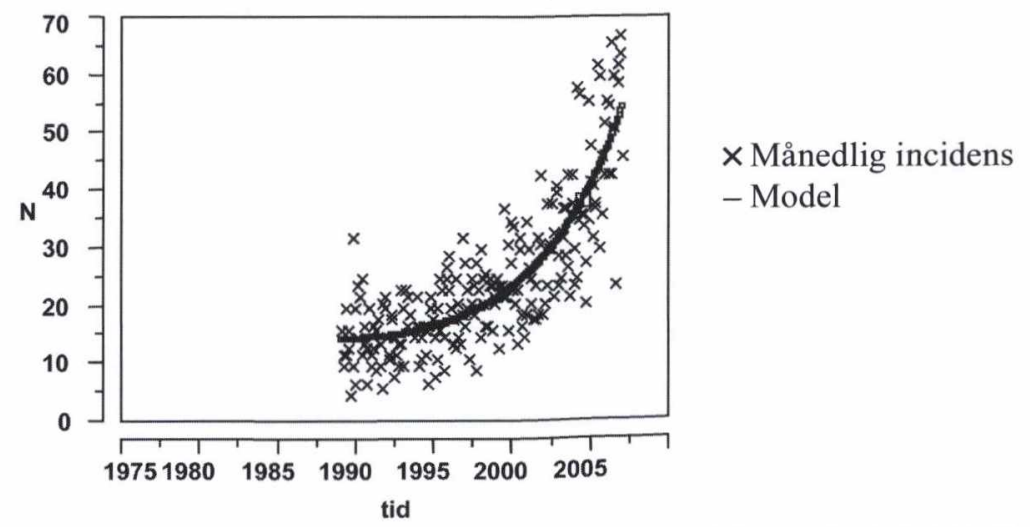

Baseres estimatet af vækstraten på incidenser fra årene 2003 til 2006 (inkl.) fås en vækstrate på $15,7 \%$ pro anno $(95 \%$ KI $[12,4 \% ; 19,0 \%])$ - vækstraten for incidensen er altså yderligere stigende i de sidste år. 
Aldersfordelingen blandt disse 1774 personer er med en median alder på 36 år og en maksimum alder på 82 år meget forskellig fra aldersfordelingen i en almindelig fængselspopulation, Tabel 1.

Tabel 1. Alder på domstidspunkt for retspsykiatriske patienter

\begin{tabular}{|c|c|c|c|c|}
\hline Minimum & $25 \%$ fraktil & Median & $75 \%$ fraktil & maksimum \\
\hline 15 & 26 & 36 & 44 & 82 \\
\hline
\end{tabular}

Andelen af kvinder blandt de 1774 personer er $17 \%$, hvilket er langt højere end andelen af kvinder i en almindelig fængselspopulation.

Desuden ses, at mænd og kvinder ikke er fordelt på samme måde i aldersgrupperne, Tabel 2; der er således relativt flere kvinder over 40 år sammenlignet med andelen af mænd i denne aldersgruppe.

Tabel 2. Samvariation af køn og alder for retspsykiatriske patienter

\begin{tabular}{|c|c|c|c|c|}
\hline \multirow{2}{*}{ Alder } & \multicolumn{2}{|c|}{ Mænd } & \multicolumn{2}{c|}{ Kvinder } \\
\cline { 2 - 5 } & $\mathrm{n}$ & $\%$ & $\mathrm{n}$ & $\%$ \\
\hline-29 & 531 & 36 & 83 & 27 \\
\hline $30-39$ & 401 & 27 & 85 & 28 \\
\hline $40+$ & 533 & 36 & 136 & 45 \\
\hline
\end{tabular}

$\chi^{2}$ test, $p=0,005$

Tabel 3 viser, at vold indgår i $68 \%$ af dommene, og at der er en tendens til, at andelen af voldsdomme er højere for kvinder ( $72 \%)$ sammenlignet med mænd (68\%), tabel 4.

Tabel 3. Fordeling af kriminalitet for retspsykiatriske patienter

\begin{tabular}{|c|c|c|}
\hline & $\mathrm{n}$ & $\%$ \\
\hline Vold * & 1.198 & 68 \\
\hline Ikke-vold $* *$ & 551 & 31 \\
\hline Ukendt & 25 & 1 \\
\hline Total & 1.774 & 100 \\
\hline
\end{tabular}

* Drab, vold, sædelighedskriminalitet, brandstiftelse og røveri

** Indbrud, tyveri, narkotika og færdselslov mv. 
Tabel 4. Samvariation af kriminalitet og køn for retspsykiatriske patienter

\begin{tabular}{|c|c|c|c|c|c|c|}
\hline \multirow{2}{*}{} & \multicolumn{2}{|c|}{ Mænd } & \multicolumn{2}{c|}{ Kvinder } & \multicolumn{2}{c|}{ I alt } \\
\cline { 2 - 7 } & $\mathrm{n}$ & $\%$ & $\mathrm{n}$ & $\%$ & $\mathrm{n}$ & $\%$ \\
\hline Vold $^{*}$ & 980 & 68 & 215 & 72 & 1.195 & 69 \\
\hline Ikke-vold $^{* *}$ & 466 & 32 & 83 & 28 & 549 & 32 \\
\hline Total & 1.446 & 100 & 298 & 100 & 1.744 & 100 \\
\hline
\end{tabular}

* Drab, vold, sædelighedskriminalitet, brandstiftelse og røveri

** Indbrud, tyveri, narkotika og færdselslov mv.

$\chi^{2}$ test, $\mathrm{p}=0,08$

Estimeres vækstraten for mænd og kvinder hver for sig, finder man, at vækstraten er (ikke signifikant) større for kvinder end for mænd, tabel 5.

Tabel 5. Arlig vakstrate for maend og kvinder for retspsykiatriske patienter

\begin{tabular}{|c|c|}
\hline & Arlig vækstrate \\
\hline Mænd & $13,1 \%$ \\
\hline Kvinder & $23,1 \%$ \\
\hline Samlet & $14,6 \%$ \\
\hline
\end{tabular}

$\mathrm{p}=0,140$

Vækstraten for voldelig og ikke-voldelig kriminalitet er den samme, tabel 6.

Tabel 6. Arlig vaekstrate for volds og ikke-volds-dømte retspsykiatriske patienter

\begin{tabular}{|c|c|}
\hline & Årlig vækstrate \\
\hline Vold & $15,7 \%$ \\
\hline Ikke-vold & $13,7 \%$ \\
\hline
\end{tabular}

$\mathrm{p}=0,685$

Estimeres vækstraterne for de tre aldersgrupper, tabel 7, ses, at det er antallet i aldersgruppen under 29, der vokser - 14,8 \% årligt - og især aldersgruppen over 40 er voksende, $21,8 \%$ årligt. Derimod er der i aldersgruppen 30 - 39 år ikke sket nogen signifikant øgning.

Tabel 7. Arlig vakstrate for tre aldersgrupper for retspsykiatriske patienter

\begin{tabular}{|c|c|}
\hline Aldersgruppe & Årlig vækstrate \\
\hline-29 & $14,8 \%$ \\
\hline $30-39$ & $5,0 \% *$ \\
\hline $40+$ & $21,8 \%$ \\
\hline
\end{tabular}

$* \mathrm{~ns}, \mathrm{p}=0,225$ 
Opdeles materialet efter både køn og alder, finder man, at vækstraterne i de tre aldersgrupper ikke er de samme for mænd og kvinder. Generelt er væksten større for kvinder end for mænd. Men det er alligevel bemærkelsesværdigt, at den største vækstrate findes i gruppen kvinder over 40 år - og den næststørste vækstrate findes blandt kvinder under 29 år.

Tabel 8. Arlig vakstrate for mand og kvinder i tre aldersgrupper af retspsykiatriske patienter

\begin{tabular}{|c|c|c|}
\hline Aldersgruppe & Mænd & Kvinder \\
\hline-29 & $13,8 \%$ & $23,4 \%$ \\
\hline $30-39$ & $3,6 \%$ & $12,3 \%$ \\
\hline $40+$ & $20,2 \%$ & $30,3 \%$ \\
\hline
\end{tabular}

$\chi^{2}$ test, $\mathrm{p}<0,001$

I et senere artikel vil vi søge at analysere de foreløbige resultater mere detaljeret, men det synes klart, at kvinder udgør en stor - og stigende - andel af de retspsykiatriske patienter.

\section{Sammenfatning}

- Retspsykiatriske patienter optager nu $20 \%$ af de psykiatriske senge.

- Antallet af psykiatriske senge falder stadig.

- Antallet af retspsykiatriske patienter stiger stadig, nu med $15 \%$ om året.

- Retspsykiatriske (skizofrene) patienter er ofte dømt for personfarlig kriminalitet.

- Kvinder udgør en stigende andel af de retspsykiatriske patienter

\section{Litteratur:}

Amtsrådsforeningen. Retspsykiatri - status og udfordringer. København: Amtrådsforeningen, 2004.

Kramp P, Lunn V, Waaben K. Retspsykiatri. København: GadJura, 1996.

Kramp P, Gabrielsen G. Retspsykiatri H:S - en spørgeskemaundersøgelse (Rapport). København: H:S Sundhedsfagligt råd for psykiatri, 2001.

Rigsadvokaten. Meddelelse $n r .5 / 2002$ og $n r .5 / 2007$. København: Rigsadvokaten, 2002, 2007.

Kramp P, Gabrielsen G. Kriminalitet begået af psykisk syge 1977 - 1999. Ugeskr Læger 2003;165:2551-6.

Kramp P, Gabrielsen G. Retspsykiatriske patienter - udvikling 2000 - 2004. Ugeskr Læger 2005;167:2269-72. 
Glenthøj BY, Mackeprang T, Bille AEH, Hemmingsen RP. Transmitterforstyrrelser hos skizofrene Ugeskr Læger 1999;161:1391-8.

Vevera J, Hubbard A, Veselý A, Papazová H. Violent behaviour in schizophrenia. Br J Psychiatry 2005;187:426-30.

O'Neill C, Sinclair H, Kelly A, Kennedy H. Interaction of forensic and general psychiatric services in Ireland: learning the lesson or repeating the mistakes? Ir J Psych Med 2002;19(2):48-54.

Hodgins S, Müller-Isberner R, Allaire J-F. Attempting to understand the increase in the numbers of forensic beds in Europe: A multi-site study of patients in forensic and general psychiatric services: Int J Forensic Mental Health 2006:5,173-84.

Addresser:

Gorm Gabrielsen

Center for Statistik

Copenhagen Business School

Solbjerg Plads 3

DK-2000 Frederiksberg

Mail: stgg@cbs.dk

Peter Kramp

Retspsykiatrisk Klinik

Blegdamsvej 6B

DK-2200 København N

Mail:pk001@retspsykiatriskklinik.dk 